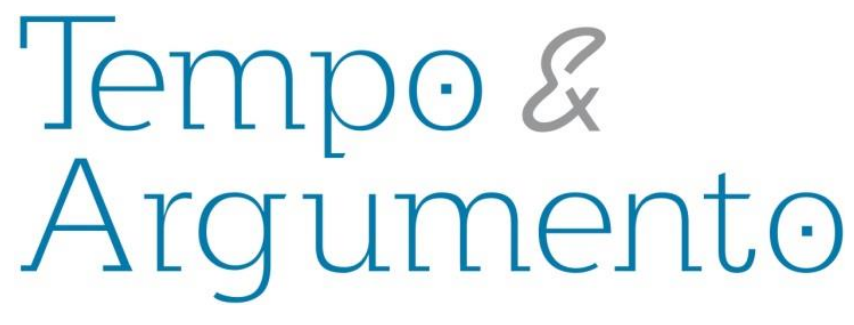

\title{
Tempo presente: entre os métiers do historiador e do jornalista
}

\begin{abstract}
Resumo
Este artigo se propõe a fazer uma comparação entre os métiers do historiador e do jornalista, situando esses ofícios dentro da corrente historiográfica chamada História do Tempo Presente, de modo que procura também descrever as origens e desenvolvimento dessa corrente em âmbito internacional e nacional, seu lugar dentro da disciplina de História e junto às outras vertentes historiográficas. Procuramos, ainda, identificar a relação entre os campos da História e da Comunicação, estabelecendo semelhanças, diferenças e seus diferentes cruzamentos.
\end{abstract}

Palavras-chave: Historiador. Jornalista. História do Tempo Presente.

\author{
José Fernando Saroba Monteiro \\ Doutorando em História na Universidade \\ Federal Rural do Rio de Janeiro (UFRRJ). \\ Seropédica - RJ - BRASIL \\ jfmonteiro2@hotmail.com
}

\section{Para citar este artigo:}

MONTEIRO, José Fernando Saroba. Tempo presente: entre os métiers do historiador e do jornalista. Tempo e Argumento, Florianópolis, v. 10, n. 24, p. 510 - 539, abr./jun. 2018.

\section{DOI: $10.5965 / 2175180310242018510$}

http://dx.doi.org/10.5965/2175180310242018510 


\title{
Present time: between the métiers of historian and journalist
}

\begin{abstract}
This article proposes to make a comparison between the métiers of historian and journalist, placing these crafts within the historiographic strand called History of the Present Time, so that it also seeks to describe the origins and development of this strand at the international and national levels, its place within History as a subject and along with the other historiographic strands. We also try to identify the relationship between the fields of History and Communication, establishing similarities, differences, and their various intersections.
\end{abstract}

Keywords: Historian. Journalist. History of the Present Time.

\section{Introdução}

É certo que os historiadores escrevem sobre o passado sempre a partir da perspectiva de seu tempo e, até mesmo, "devemos estar preparados para ler cada um dos textos clássicos "como se tivessem sido escritos por um contemporâneo nosso"” (SKINNER, 2005, p. 81-82). No entanto, a dificuldade aumenta consideravelmente quando se deve escrever "sobre o seu próprio tempo", "sobre o tempo em que se vive", ou seja, "sobre o tempo presente". E esse é o intuito da História do Tempo Presente: contar a história dos nossos dias, da atualidade. É nesse contexto que o métier do historiador se confunde com o métier do jornalista. 
Os historiadores costumam explicar o presente por meio do passado, enxergar o presente como resultado do tempo passado ou mesmo ver a História como arauto de todo o conhecimento necessário ao presente. Essa última ideia corresponde à concepção de historia magistra vitae, preconizada por Cícero e tão bem desenvolvida por Reinhart Koselleck (2006, p. 41-60), na qual a História, "mestra da vida", traz todos os ensinamentos que precisamos para o presente e para os prognósticos futuros. Seguindo esse mesmo pensamento, Pierre Nora (1979) ressalta que a História Contemporânea é condenada a viver "à sombra" do passado, notadamente, da Antiguidade, da Idade Média e dos Tempos Modernos, os quais influenciam o presente tornando-o, como já dissemos, produto do passado.

Entretanto, sabemos que a contemporaneidade é marcada por mudanças não encontradas em períodos anteriores, até mesmo quanto às angústias e aos questionamentos do homem atual, ou pós-moderno, o qual, segundo Stuart Hall (2006, p. 73-74), mantém uma identidade "móvel" e "flutuante", e mesmo que reconheçamos que não se construiu em um dia e tem todas as suas referências em eventos passados, é este mundo atual, efêmero e de evolução acelerada, no qual o imediatismo ganha cada vez mais terreno e os acontecimentos são noticiados quase que instantaneamente, em nível global, que o historiador do tempo presente procura compreender e, mais do que isso, recontá-lo de modo a inseri-lo na estrutura muito mais ampla da História.

Há muitas questões que tangem o presentismo e a contemporaneidade, sem dúvida, uma das mais interessantes é aquela sobre a modernidade e a pós-modernidade. Sabe-se que a modernidade é um conjunto de fatores nos quais as sociedades estiveram inseridas desde aproximadamente o século $\mathrm{XV}$, mas, muito se vem falando sobre o esgotamento dessa estrutura e o surgimento de uma outra, a pós-modernidade. Porém, especificamente, onde terminaria uma e onde se iniciaria a outra? Alguns apontam o início da pós-modernidade já no início do século XX, quando, de fato, a industrialização e os avanços técnico-científicos, especialmente quanto aos meios de comunicação e informação, configuraram uma nova sociedade. Isso também nos leva a indagar sobre em que momento se inicia o tempo presente? E como se delimitariam os períodos históricos dentro desse novo contexto? Sabe-se que os estudos históricos sobre o presente se 
iniciam, em grande parte, a partir do pós-Segunda Guerra, mas já se viu eventos como a Queda do Muro de Berlim e o 11 de Setembro ${ }^{1}$ como síntese do mundo contemporâneo, tal como o foi a Revolução Francesa para o encerramento da Idade Moderna ou a fundação da Idade Contemporânea. Em uma tentativa de continuidade de nomeação dos diferentes períodos históricos, poderíamos apontar esses eventos atuais (ou a Primeira Guerra $^{2}$ ou a Segunda Guerra como também se sugere 3 , ou algum outro de maior significância que venha a ocorrer) também como momentos finais de uma era, que denominamos Idade Contemporânea, e esta passaria, então, a ser Idade Pós-Moderna, pois sucede imediatamente a Idade Moderna. Tudo que vier depois passa a ser o Contemporâneo, ou seja, o atual. Helena Muller (2007, p. 18-19) chega a dividir os historiadores do presente em dois grupos: os da modernidade e os da pós-modernidade, sendo os primeiros o alicerce para a história, mas só considerando os estudos feitos até a Segunda Guerra Mundial; já os seguintes não se retêm, necessariamente, nas noções de presente e passado para a escolha de seus estudos. Não obstante, o presente está inserindo-se cada vez mais no campo da História, o que de fato sugere e requer uma revisão historiográfica.

\section{A história do tempo presente}

O historiador alemão Reinhart Koselleck (2006, p. 295) nos fala sobre o Zeitgeist (“espírito do tempo"), expressão que, segundo ele, foi amplamente difundida e pode ser atribuída a gerações criativas, como a do Sturm und Drang. De acordo com Pieter Lagrou (2009), a partir da década de 1930 também se difundiu na Alemanha a expressão Zeitgeschichte, que seria a própria história de seu tempo. No entanto, ainda segundo Lagrou (2009), é somente na década de 1970 que é introduzida na França a expressão

\footnotetext{
${ }^{1}$ Cf. HARTOG, François. Regimes de historicidade. Belo Horizonte: Autêntica, 2013, p. 136 e 188. Ver também: MAUAD, Ana Maria. Dimensões do presente: palavras e imagens de um acontecimento, os atentados ao World Trade Center e ao Pentágono, em 11 de setembro de 2001. In: PÔRTO, Gilson (Org.). História do tempo presente. Bauru, SP: Edusc, 2007. p. 223-263. E, ainda: FERREIRA, Marieta de Moraes. História do tempo presente: desafios. Cultura Vozes, Petrópolis, v. 94, n. 3, p. 9, maio/jun. 2000.

${ }^{2}$ Cf. ROUSSO, Henry. A história do tempo presente, vinte anos depois. In: PÔRTO JR., Gilson (Org.). História do tempo presente. Bauru, SP: Edusc, 2007, p. 279 e p. 285-286.

${ }^{3}$ Cf. LAGROU, Pieter. Sobre a atualidade da história do tempo presente. In: PÔRTO JR., Gilson (Org.). História do tempo presente. Bauru, SP: Edusc, 2007, p. 37.
} 
"História do Tempo Presente", praticada por um grupo que queria se diferenciar da historiografia que até aquele momento voltava os olhos para o século anterior. A expressão francesa foi claramente inspirada na expressão alemã, o que também ocorreu na Holanda (Eigentijdse Geschiedenis).

Patrick Garcia (2003, p. 2, tradução nossa) destaca que: “Tucídides, general e historiador ateniense da Guerra do Peloponeso, é frequentemente invocado como figura fundadora de uma escrita 'a quente' da história, que não mais, desde então, deixou de existir, malgrado alguns eclipses". Entre esses eclipses, apesar de historiadores como Montesquieu, Tocqueville, Michelet e Marx já realizarem trabalhos em beneficio do presente $^{4}$, há aquele desencadeado a partir de finais do século XIX e instituído pela primeira geração da École des Annales, que refutaram a produção historiográfica anterior por considerá-la "elitista, anedótica, individualista, factual, subjetiva e psicologizante”, aderindo, a partir daí, a uma nova concepção econômica e social.

Esses postulados foram seguidos até a Terceira Geração dos Annales, quando surge a Nova História, a partir da qual, embora a maioria dos historiadores rejeitasse a História Contemporânea, sendo Pierre Nora e Jacques Le Goff duas exceções, cresce um interesse pela história do século XX, já no período pós-Segunda Guerra, primeiro creditada a instituições especializadas e, somente depois, a partir da década de 1970, integrando outras instituições de investigação e Ensino Superior ${ }^{6}$. Entretanto, a agitação do novecentos logo despertou o interesse de muitos historiadores, que se preocuparam em fazer uma investigação mais eficaz sobre o presente. Bem lembrou Jacques Le Goff (1999, p. 101) que o futuro (e podemos incluir aí o presente) não é “inteiramente determinado pelo passado" e há que se reconhecer que no mundo acelerado e de grande profusão em muitos aspectos, como tem sido o nosso a partir do século XX, os

\footnotetext{
${ }^{4}$ Cf. MULLER, Helena Isabel. História do tempo presente: algumas reflexões. In: PÔRTO JR., Gilson (Org.). História do tempo presente. Bauru, SP: Edusc, 2007, p. 26.

${ }^{5}$ Cf. FERREIRA, Marieta de Moraes. História do tempo presente: desafios. Cultura Vozes, Petrópolis, v. 94, n. 3, p. 115, maio/jun. 2000.

${ }^{6}$ Cf. LAGROU, Pieter. A história do tempo presente na Europa depois de 1945: como se constituiu e se desenvolveu um novo campo disciplinar. Revista Eletrônica Boletim do Tempo, São Cristóvão, v. 4, n. 15, 2009.
} 
historiadores não poderiam aceitar uma História Contemporânea que se findasse já na Segunda Guerra Mundial.

Agnès Chauveau e Philippe Tétart (1999, p. 9-15) afirmam que os três fatores que levaram os historiadores a desenvolver o interesse pelo presente foram: a Nova História Política, ou seja, a renovação do campo político dentro da historiografia, notadamente, encabeçada por René Rémond; o impacto “de geração”, ou o surgimento da consciência de geração; e o fenômeno da "demanda social”, as inúmeras mudanças no quadro social, tais como avanços tecnológicos, mídias e fortalecimento de ideologias, a partir dos anos 1950-60. Chauveau e Tétart (1999, p. 13) ainda ressaltam a importância da coleção “A História Imediata", lançada em 1963, por Jean Lacouture, como uma das pedras fundamentais para a história do presente.

O interesse pelo presente logo reuniu os historiadores franceses em torno de uma nova instituição: o Instituto de História do Tempo Presente (IHTP). Fundado em 1978, o IHTP foi responsável pelas primeiras obras de referência da nova disciplina, em geral obras coletivas, com destaque para o Bulletin de l'IHTP e para a coleção "Histoire du Temps Présent", publicadas a partir de 1998. François Bédarida, fundador e primeiro diretor do instituto, falou sobre as primeiras produções: “O primeiro número do Bulletin de l'IHTP trazia um editorial que orgulhosamente intitulei 'A nova oficina de Clio'. Era realmente um momento propício ao espírito criativo, à inovação, à audácia de uma aventura intelectual coletiva" (BÉDARIDA, 1998, p. 219). Duas outras grandes obras dentro dessa agenda também são Questions à l'histoire des temps présents (1992) ${ }^{7}$, organizado por Agnès Chauveau e Philippe Tétart, com edição brasileira de 1999, e Écrire I'histoire du temps présent: Étude en hommage à François Bédarida (1993), obra coletiva concebida em homenagem ao fundador do instituto.

Para além do IHTP, o Institute for Contemporary History na King's College London, fundado em 1986, também tem contribuído na promoção da história de um passado recente, a qual é englobada na Contemporary History e que, junto com a escola francesa e

\footnotetext{
${ }^{7}$ Rodolfo Fiorucci (2011) chama a atenção para o fato de muitos dos autores de Questões para a história do presente, também terem participado na publicação de Por uma história política (1988), mostrando, portanto, uma continuidade com o grupo de Rémond, em Nanterre, e, consequentemente, com a Nova História Política.
} 
a Zeitgeschichte alemã, tem impulsionado o campo da História do Tempo Presente. Também vale destacar no quadro europeu o Instituto de História Contemporânea (IHC), da Universidade Nova de Lisboa.

No período pós-guerra, houve uma crescente tentativa de unificação por parte do Mundo Ocidental, o que, em grande parte, favoreceu o desenvolvimento da globalização. Esse novo contexto, no qual as inter-relações aumentam e as distâncias diminuem, dinamizou as sociedades atuais, ocasionando o surgimento de inúmeros debates, tais como: o homem no mundo globalizado e suas relações sociais, econômicas, políticas e culturais, dentro dos planos locais, nacionais e internacionais; as novas tecnologias e os meios de comunicação; o papel das mídias (rádio, televisão, cinema, internet) e a aceleração e velocidade do conhecimento e informação. Eric Hobsbawm (1998, p. 247248) destaca que, no decorrer do que ele chamou de o "breve século XX": "Jamais o mundo, ou seja, as vidas dos homens e mulheres que vivem no planeta, foi transformado de modo tão profundo, dramático e extraordinário em tão breve período". Esses novos questionamentos também se inserem no campo científico, renovando o campo das ciências, inclusive humanas (Filosofia, Sociologia etc.), certamente, cabendo uma parcela à História, que se inclui nesses debates por meio de novas correntes historiográficas, como História da Informática, História Global, História das Relações Internacionais, MicroHistória, História e Ficção, a própria História do Tempo Presente, entre outras. François Dosse (2012, p. 60) ressalta que a presentificação do mundo contemporâneo globalizado, resultou em uma nova "experimentação da historicidade". Na história do presente, o historiador coexiste com seus próprios objetos e testemunhas, estando no front dos acontecimentos (para parodiar uma expressão de Pierre Nora ${ }^{8}$ ), sendo ele mesmo parte da História, o que Lagrou (2007, p. 35) comparou à participating observation dos antropólogos.

A História do Tempo Presente, bem como boa parte da produção historiográfica recente, é marcada por uma massificação de fontes, que se renovaram e se expandiram,

\footnotetext{
${ }^{8}$ Cf. NORA, Pierre. O retorno do fato. In: LE GOFF, Jacques; NORA, Pierre. História: novos problemas. 2. ed. Rio de Janeiro: Francisco Alves, 1979, p. 180. Ver também: MAUAD, Ana Maria. Dimensões do presente: palavras e imagens de um acontecimento, os atentados ao World Trade Center e ao Pentágono, em 11 de setembro de 2001. In: PÔRTO, Gilson (Org.). História do tempo presente. Bauru, SP: Edusc, 2007. p. 227.
} 
especialmente por meio dos avanços tecnológicos mais recentes. Lucília Delgado e Marieta de Morais Ferreira descrevem bem a grande diversidade de recursos documentais que a história do presente acabou englobando:

[...] são eles: documentos audiovisuais, fotografias ${ }^{9}$, escritos literários, relatos orais e escritos, charges, CD-ROMs, filmes documentários, diferentes suportes da informática, plantas, mapas, atas, programas de rádio, peças publicitárias, jornais, revistas, músicas, entre outros (DELGADO e FERREIRA, 2014, p. 8).

Também por essa abundância, o historiador deve saber selecionar as fontes mais confiáveis, tomando cuidado para que suas próprias produções não se rendam a superficialismos, ocasionando a "vulgarização" 10 ou "banalização"11 da história. Ainda segundo Delgado e Ferreira (2014, p. 7):

A história do tempo presente tem mobilizado segmento expressivo da comunidade de historiadores no plano nacional e internacional. Inscrevese em um movimento mais amplo de renovação historiográfica que trouxe consigo revitalização da história política, ampliação do uso de fontes, valorização da interdisciplinaridade, maior diálogo com as ciências sociais, recusa de explicações deterministas e totalizantes, valorização de atores individuais e coletivos, relação dialética entre história e memória.

Com toda a certeza, a História do Tempo Presente se beneficia muito com o uso da memória e, consequentemente, da História Oral, ou seja, depoimentos, testemunhos, entrevistas etc. ${ }^{12}$, mas estes, muitas vezes, são formados no "calor do momento", o que impede a imparcialidade dos depoentes. Apesar da reconhecida importância da “testemunha ocular”, acredita-se que a história só vem a enriquecer na medida em que avança para o passado e que os acontecimentos se recobrem de névoa de seus

\footnotetext{
${ }^{9}$ Mauad destaca que, já durante a Guerra Civil americana, quando equipe de Mathew Brady fez a cobertura fotográfica dos acontecimentos, "o relato histórico ganhava [...] a força comprobatória da verdade fotográfica" (MAUAD, 2007, p. 230).

${ }^{10}$ Cf. LE GOFF, Jacques. A visão dos outros: um medievalista diante do presente. In: CHAVEAU, Agnès; TÉTART, Philippe (Org.). Questões para a história do presente. Bauru, SP: Edusc, 1999, p. 99.

${ }^{11}$ Cf. LAGROU, Pieter. Sobre a atualidade da história do tempo presente. In: PÔRTO JR., Gilson (Org.). História do tempo presente. Bauru, SP: Edusc, 2007, p. 37. Ver também: ROUSSO, Henry. A história do tempo presente, vinte anos depois. In: PÔRTO JR., Gilson (Org.). História do tempo presente. Bauru, SP: Edusc, 2007, p. 277-279.

${ }^{12}$ Cf. FRANK, Robert. Questões para a fonte do presente. In: CHAVEAU, Agnès; TÉTART, Philippe (Org.). Questões para a história do presente. Bauru, SP: Edusc, 1999. p. ${ }^{13}$. Ver também: FERREIRA, Marieta de Moraes; AMADO, Janaína. Usos e abusos da história oral. Rio de Janeiro: Ed. FGV, 1998.
} 
contemporâneos, que vai se dissipando somente ao longo do tempo ${ }^{13}$. Também por isso, Lagrou (2009) conclui que, para Lucien Febvre "a história do tempo presente se faz mais do reconhecimento de uma dívida moral para com os mártires e os testemunhos, e por conseguinte, desta comemoração do que com a própria historiografia científica”. No entanto, a história do presente, que havia sido apreciada desde a Antiguidade, mas recusada, como vimos, a partir do fim do século XIX, teve seu retorno e não podemos deixar de perceber a necessidade dos historiadores acompanharem as mudanças mais recentes; se antes o presentismo era um privilégio dos sociólogos, jornalistas, politólogos etc., hoje, não mais. Aliás, seria uma negligência, por parte da História, não acompanhar o presente, além de um impedimento ao seu desenvolvimento como ciência, de suas questões teórico-metodológicas e da compreensão do papel do historiador - este servindo mesmo como ator, o que confere ainda mais originalidade à história do presente.

A História do Tempo Presente é tangida pela presença constante do tempo em construção e, se por um lado isso pode auxiliar na compreensão dos acontecimentos em andamento $^{14}$, uma das grandes críticas que se faz é justamente o imediatismo com que ela é passada - que além de poder torná-la obsoleta ou deixar o historiador sujeito aos modismos e climas ideológicos ${ }^{15}$, não proporciona um tempo maior para a reflexão sobre dado acontecimento, chamando a atenção mesmo para a diferença entre o acontecimento e o próprio fato histórico. Fugindo dessas questões, Braudel propôs o conceito de "longa duração"16, em detrimento do événementielle, sendo seguido pela maioria dos historiadores, o que em parte impediu o desenvolvimento da história do presente. Nesse contexto, devemos perceber, ainda, que a história do presente procura os acontecimentos mais recentes, restringindo-se a períodos menores ("curta duração”), utilizando escalas reduzidas e inserindo-se no campo da Micro-História.

\footnotetext{
${ }^{13}$ Cf. GOTTLIEB JAKOB PLANCK apud KOSELLECK, Reinhart. Futuro passado: contribuição à semântica dos tempos históricos. Rio de Janeiro: Contraponto, 2006, p. 174.

${ }^{14}$ Cf. FERREIRA, Marieta de Moraes. História do tempo presente: desafios. Cultura Vozes, Petrópolis, v. 94, n. 3, p. 115, maio/jun. 2000, p. 120.

${ }^{15}$ Cf. SIRINELLI, Jean-François. Ideologia, tempo e história. In: CHAVEAU, Agnès; TÉTART, Philippe (Org.). Questões para a história do presente. Bauru, SP: Edusc, 1999.
}

${ }^{16}$ Cf. BRAUDEL, Fernand. História e ciências sociais. A longa duração. In: BRAUDEL, Fernand. Escritos sobre a história. São Paulo: Perspectiva, 2009, p. 41-78. 
Também podemos diferenciar a "história imediata" da própria "história do presente"; embora sejam genericamente utilizadas como sinônimos, notamos que, enquanto a primeira se concentra nos fatos mais instantâneos, "do agora", e nesse ponto se aproximando mais da atividade jornalística, a outra exige um recuo maior, ainda que também recente, e, consequentemente, um maior embasamento histórico. Ainda assim, Chauveau e Tétart (1999, p. 21) defendem que "a leitura imediata pertence ao presente antes que ao imediato em sua definição primitiva de instante”. Todavia, François Dosse (2012, p. 168) julga que a história do presente não envolve apenas o "muito próximo", "ela é também uma história diferente, que participa das novas orientações de um paradigma que se busca na ruptura com o tempo único e linear e que pluraliza os modos de racionalidade".

Devemos destacar, também, alguns entraves à produção da História do Tempo Presente, por exemplo: a efemeridade das fontes, em virtude da velocidade das informações no mundo atual, especialmente quanto aos meios digitais, o que pode leválas ao desuso ou ao menos a uma necessidade de revisão; a dificuldade da imparcialidade por parte do historiador, pois há uma linha muito tênue entre o presente e o historiador e não há, ou quase não há, alteridade, é-lhe intrínseca, ou seja, é ele mesmo ou termina por representar a testemunha dos acontecimentos, o que leva ao subjetivismo ${ }^{17}$; e a constante corrida atrás do tempo, ou a ânsia de alcançar os acontecimentos mais recentes, o que por vezes é impossível e estremece o próprio ofício do historiador. Também vale mencionar o questionamento sobre até que ponto a história permanece presente, pois, decorrido algum tempo ela não é mais presente e, daí em diante, só pode ser considerada história presente se levarmos em conta que foi produzida em um momento próximo do acontecimento.

Henry Rousso (2007, p. 277-309) reforça o fato da História do Tempo Presente não estar mais buscando espaço em meio à produção historiográfica e não representa mais uma "ruptura epistemológica", já sendo reconhecida e contando com razoável produção, mas, ainda assim, permanece como "uma questão aberta no plano teórico", em grande

\footnotetext{
${ }^{17}$ Cf. PUENTES, Johnny Alarcón; GAVÍDIA, J. L. Mozant. História e historiografia: construção de novas
} tendências teóricas. In: PÔRTO JR., Gilson (Org.). História do tempo presente. Bauru, SP: Edusc, 2007. 
parte procurando legitimação, até mesmo em virtude de sua volatilidade. Patrick Garcia (2003, p. 5, tradução nossa) chamou a atenção justamente para isso ao dizer que:

A baixa legitimidade, a despeito do salto institucional que representa a criação do Instituto e o recrutamento de pesquisadores, conduziu o IHTP a liderar uma reflexão historiográfica e epistemológica pouco habitual no meio histórico. Ela é organizada no quadro de seminários do laboratório e acompanha o desenvolvimento de pesquisas empíricas, de acordo com a extensão do campo suportado pelo IHTP, para assumir finalmente a forma de um livro-programa: Écrire l'histoire du temps présent. Este, a partir do qual, se construiu a noção de História do Tempo Presente.

Podemos citar, ainda, iniciativas como a dos historiadores que, não se restringindo à abordagem metodológica e epistemológica da disciplina, produzem obras “conteudistas", mas com foco também no tempo presente. É o caso, como destaca Lagrou (20097 [esta obra é de 2007, são duas obras do mesmo autor, a de 2009 é online não paginada], p. 32), de History of the present, obra publicada em 1999 por Timothy Garton Ash, que fazia esboços de acontecimentos ocorridos na Europa Central a partir de 1989. Iniciativa semelhante ocorreu no Brasil, com a publicação de História do tempo presente (2003), volume 7 da coleção “Textos e Documentos”, organizada por Adhemar Marques, Flávio Berutti e Ricardo Faria, que abrange os grandes acontecimentos no mundo a partir da Guerra Fria, mas, como o próprio livro alerta, vem mais como um complemento da História Contemporânea, publicada no volume 5 da mesma coleção.

No Brasil, essa disciplina, que ainda caminha a passos lentos, teve como precursora a obra História do tempo presente, idealizada e organizada por Gilson Pôrto Jr., que conseguiu reunir, como ele mesmo destaca no prefácio da obra: "17 capítulos, fruto do trabalho em rede de 19 pesquisadores, de universidades públicas e particulares do Brasil e de 5 outras universidades estrangeiras na Argentina, na França, na Itália, em Portugal e na Venezuela" (PÔRTO JR., 2007, p. 13). Em 2014, Marieta de Moraes Ferreira e Lucilia de Almeida Neves Delgado também fizeram uma considerável contribuição com a obra História do tempo presente, na qual há uma ótima sistematização da disciplina e sobre o enquadramento do historiador nessa nova agenda. Também se apresenta como uma boa contribuição o capítulo "História, memória e tempo presente" (MOTTA, 2012), incluído na obra Novos domínios da história (2012), organizada por Ciro Flamarion Cardoso 
e Ronaldo Vainfas, uma atualização da anterior e famosa obra Domínios da história (1997). Também ganhou destaque o trabalho pioneiro do Laboratório do Tempo Presente (Tempo), da Universidade Federal do Rio de Janeiro (UFRJ), criado em 1994, que manteve a revista Boletim Eletrônico do Tempo Presente e, ainda, o Laboratório de Estudos do Tempo Presente (LabTempo), da Universidade Estadual de Maringá (UEM), a Revista Agora e os Cadernos do Tempo Presente, da Universidade Federal de Sergipe (UFS).

Márcia Maria Menendes Motta (2012, p. 33) afirma que é possível asseverar que boa parte dos estudos sobre o tempo presente no Brasil têm como marco inicial o golpe de 1964 e seus desdobramentos. Nesse contexto, vale destacar trabalhos como os de Nelson Werneck Sodré ${ }^{18}$ e Daniel Aarão Reis Filho ${ }^{19}$, que apresentam visões privilegiadas dos fatos, sendo que, cada um ao seu modo (o primeiro militar e o segundo guerrilheiro), teve participação direta nos eventos. Além, é claro, dos inúmeros trabalhos que vieram posteriormente a discutir o assunto e outros que ainda hoje o fazem, tendo por tema, por exemplo, as Comissões da Verdade ${ }^{20}$, instauradas a partir de 2011, ou as aberturas de arquivos sigilosos, os quais Carlos Fico (2012, p. 43-59) chama de “documentos sensíveis". Outros temas abordados são as relações internacionais, a globalização, os meios de comunicação, as novas tecnologias, migração, terrorismo, entre outros.

\section{História e comunicação}

História e Comunicação, além de pertencerem ao campo das Ciências Humanas e das Ciências Sociais, também apresentam outras similaridades e cruzamentos diversos. É comum, por exemplo, falarmos em História da Comunicação, História do Jornalismo, História da Imprensa, História dos Meios de Comunicação ou mesmo História da

${ }^{18}$ Cf. SODRÉ, Nelson Werneck. Memórias de um soldado. Rio de Janeiro: Civilização Brasileira, 1967. Ver também: SODRÉ, Nelson Werneck. Memórias de um escritor. Rio de Janeiro: Civilização Brasileira, 1970.

19 REIS FILHO, Daniel Aarão. As organizações comunistas e a luta de classes no Brasil: 1961-1968. Tese (Doutorado) - Programa de Pós-Graduação em História Social, Universidade de São Paulo, 1987. Cf. REIS FILHO, Daniel Aarão. A revolução faltou ao encontro. São Paulo: Brasiliense, 1990.

${ }^{20}$ Cf. MACIEL, Suellen Neto Pires. Disputas da memória: uma reflexão inicial sobre a lei de criação da Comissão Nacional da Verdade: In: DELGADO, Lucília de Almeida Neves; FERREIRA, Marieta de Moraes (Org.). História do tempo presente. Rio de Janeiro: Ed. FGV, 2014. Ver também: SALGADO, Lívia de Barros. Narrativas de dor e silêncio: tortura, clandestinidade e exílio na vida de homens e mulheres durante a ditadura brasileira. 149 f. Dissertação (Mestrado) - Programa de Pós-Graduação em Ciências Sociais, Universidade Federal Rural do Rio de Janeiro, 2015. 
Propaganda, História da Publicidade etc. E não é raro a História se apropriar de recursos da Comunicação, especialmente quanto às fontes, como veremos adiante, além das mídias também já se fazerem presentes no próprio cotidiano do historiador; quando vai redigir um texto, por exemplo, usa um computador e quando vai publicá-lo, um livro - e, praticamente durante todo o tempo, até quando ensina, o historiador recorre a alguma mídia para exercer seu ofício.

Dentre as diferentes possibilidades de cruzamentos entre a História e a Comunicação temos a própria compreensão do presente, pois o historiador não só enxerga o presente como resultado do passado, mas também o passado como construção do presente. E como compreender esse presente sem o auxílio da Comunicação, das mídias, das notícias dos jornais, das matérias de revistas, das reportagens de TV, do rádio ou dos artigos e vídeos on-line etc.? Além disso, podem os historiadores fazer pesquisas sobre a imprensa, sobre as mídias, sobre a publicidade etc.? Por outro lado, como pode a Comunicação produzir material sem levar em conta a construção histórica, de suas mídias, de suas pautas e de sua própria produção precedente? Também podem os comunicólogos realizar pesquisas sob uma perspectiva histórica? São questões que parecem se responder sozinhas, pela obviedade da necessidade desses entrelaçamentos.

Em 2008 foi comemorado o bicentenário da imprensa no Brasil, o que foi muito importante para os pesquisadores da História da Comunicação e da Mídia no país, pois, segundo Ana Paula Goulart Ribeiro e Micael Herschmann (2008, p. 13), isso estimulou o "desenvolvimento de novos trabalhos na área e [deu] grande visibilidade aos já existentes”. Ainda de acordo com Ribeiro e Herschmann (2008), a Comunicação no Brasil sofre de "presentismo", privilegiando aspectos relacionados à contemporaneidade, como pós-modernidade, globalização, novas tecnologias etc., e relegando a análise histórica a um segundo plano. Isso, é claro, se desconsiderarmos a história do presente, aqui em foco. E os autores acrescentam que também há poucos trabalhos relevantes sobre a História da Comunicação no campo da História. Ainda assim, Ribeiro e Herschmann (2008, p. 14-15) descrevem inúmeras iniciativas dedicadas a produções dentro da História da Comunicação ou ao cruzamento entre essas duas ciências, entre 
elas, apesar de indicarem ser apenas "nichos acadêmicos", destacam pesquisas sobre imprensa, televisão, jornalismo, telenovela etc., às quais poderíamos também acrescentar a música ${ }^{21}$, embora reforcem que "as discussões teóricas e metodológicas ainda são escassas”. Em resumo, Ribeiro e Herschmann (2008, p. 17) concluem que:

O que se constata - mas pouco se discute no meio acadêmico - é que construir um trabalho no âmbito da História da Comunicação (ainda que a partir de um objeto de estudo bastante delimitado) implicaria um empenho, por parte dos pesquisadores, na articulação de inúmeras informações, não só de diferentes esferas, sejam elas [de natureza] econômica, social, cultural e política, como também de distintos âmbitos - individual e coletivo. Ou melhor, exigiria a elaboração de estratégias metodológicas que permitissem correlacionar e analisar a dinâmica da vida social como um todo.

Luiz Martino (2008, p. 29) destaca a dificuldade de encontrar livros e artigos sobre História da Comunicação e enfatiza que, devido a isso, há plena aceitação da obra Uma história social da mídia: de Gutenberg à internet, de 2004, de Asa Briggs e Peter Burke, na bibliografia dos cursos de Comunicação, a qual ele acredita reunir algumas mazelas. Nesse mesmo contexto, Ribeiro e Herschmann (2008) destacam que é preocupante o fato da obra História da imprensa no Brasil, de Nelson Werneck Sodré, escrita em 1966, ainda permanecer como o principal texto de síntese sobre a História dos Meios de Comunicação no Brasil. Malgrado, Martino (2008) também alerta para a diferença entre historiadores e comunicólogos no modo de compreender os meios de comunicação: em linhas gerais, enquanto para os primeiros as mídias servem para produzir documentos que os possibilite um acesso ao passado, os outros veem os meios de comunicação como tecnologias geradoras de uma matriz social, pertencendo, portanto, à esfera pública, à atualidade, ao presente. Martino (2008) também fala sobre diferentes possibilidades de abordagem da História (ou "Histórias") da Comunicação, tais como: História dos estudos e das teorias da Comunicação; História da Linguagem; História dos Meios; História das Instituições do Campo Comunicacional; História da Publicidade, da Propaganda e das

\footnotetext{
${ }^{21}$ Cf. CALABRE, Lia. A era do rádio. Rio de Janeiro: Zahar, 2002. Ver também: MONTEIRO, José Fernando S. Música na TV: a televisão na difusão da música popular brasileira e a mimese através dos programas musicais. In: ALBUQUERQUE, Luiz Botelho; ROGÉRIO, Pedro; NASCIMENTO, Marco Antonio (Org.). Educação musical: reflexões, experiências e inovações. Fortaleza: Ed. UFC, 2015, p. 121-148. .
} 
Relações Públicas; e História dos Sistemas Sociais de Comunicação. Quanto às questões epistemológicas, Martino (2008), citando Michael Schudson, apresenta três categorias:

a) Macro-história, a que é representada pelos trabalhos de Innis, McLuhan, Ong e Godoy; b) a História da Comunicação propriamente dita, aquela que é definida como a relação dos meios com a História cultural, política, econômica, social, e representada pelos trabalhos de Habermas sobre a esfera pública e de Eisenstein sobre a imprensa; c) História das instituições, categoria muito parecida com a que apresentamos acima (MARTINO, 2008, p. 38-39).

McLuhan e Fiore (1971) mostram que há, de fato, uma estreita relação entre a História e a Comunicação, fazendo uma verdadeira incursão pela História da Humanidade para introduzir seu conceito de "aldeia global”. De acordo com Márcio Souza Gonçalves e Ericson Telles Saint Clair (2008, p. 50), realmente há uma concepção histórica clara na obra de McLuhan, na qual: "a história humana é a de uma unidade primeira [tribal], perdida com a ascensão do alfabeto fonético e posteriormente, mas importante, das técnicas de impressão em série inauguradas por Gutemberg”.

Peter Burke (2008, p. 61) lembra que é um grande desafio analisar a Comunicação na História da Humanidade:

[...] as origens da linguagem remontam há pelo menos cinquenta mil anos, possivelmente a cinco ou seis milhões de anos. As pinturas nas cavernas de Lascaux têm pelo menos vinte mil anos, enquanto a escrita tem uma história de cinco mil anos ou mais.

O autor também ressalta que a grande dificuldade de remontar esses períodos é a escassez de fontes (BURKE, 2008, p. 63) e só podemos reconstruí-los indiretamente, relacionando-os a comunicações orais com registros escritos ou em meios pós-escrita, como cilindros, disco e fitas (e, nos dias de hoje, podemos incluir os registros digitais). 0 historiador também destaca que a humanidade desenvolveu diversas formas de oralidades, para o caso africano (e poderíamos incluir outros) ele sugere a utilização de termos como "arte verbal", "literatura oral" ou "gêneros de fala" e acrescenta que: "esse sistema oral foi modificado por três revoluções na comunicação: o desenvolvimento da escrita, da imprensa e, finalmente, do que poderíamos chamar, por conveniência, de mídia eletrônica, especialmente o rádio, a televisão e a internet" 
(BURKE, 2008, p. 65). Nesse mesmo sentido, Nízia Villaça (2008, p. 254) lembra que: "a escrita e a imprensa, a telegrafia, o rádio, a telefonia, a televisão e a internet ofereceram e oferecem novas maneiras de administrar a informação e comunicá-la". Pierre Nora (1979), por sua vez, considera que os mass media são responsáveis por intermediar o acontecimento e nós, público espectador, transformando em ato (ou fato) aquilo que consistiria apenas em "palavras ao ar", marcando a irreversibilidade do gesto, embora também haja a espetacularização desses acontecimentos. Para o autor:

[...] o acontecimento moderno se apresenta mais vantajoso [para o historiador]. [...] antes de sua elaboração, antes do trabalho do tempo. [...] os media impõem imediatamente o vivido como história, e que o presente nos impõe em maior grau o vivido (NORA, 1979, p. 183-184).

Em nossa contemporaneidade, que já foi chamada de Idade Mídia ${ }^{22}$, os historiadores têm entre as mídias uma infinidade de fontes às quais podem recorrer, que são: documentos impressos e digitais (jornais, revistas, livros etc.), áudios (de rádio, depoimentos, entrevistas, músicas etc.), audiovisuais (de TV, filmes, documentários, vídeos on-line etc.) e textos e hipertextos on-line (sites, blogs, redes sociais etc. $)^{23}$. Também temos entre os "simulacros" importantes documentos para o historiador, a exemplo de produções ficcionais, como as novelas e minisséries de época, textos literários, peças teatrais, filmes e outras representações mais específicas e até transmitidas por canais especializados, como o History Channel, por exemplo.

Hérica Lene e Francisca Selidonha (2012, p. 31-44) observam nos estudos em que ocorrem cruzamentos entre Comunicação e História, a utilização do método indiciário, pertencente à Micro-História e tratado por Carlo Ginzburg em Mitos, emblemas e sinais, de 1989, que consiste em uma pesquisa detalhada e minuciosa, beirando a exaustão, mantendo um caráter detetivesco e evidenciando o inviável. Lene e Selidonha (2012) apontam a obra História cultural da imprensa, publicada em dois volumes (BARBOSA, 2007, 2010), como exemplo do emprego do método indiciário. Barbosa (2010, p. 14), por

\footnotetext{
${ }^{22}$ Cf. RUBIM, Antonio Albino Canelas. A contemporaneidade como idade mídia. Interface - Comunicação, Saúde, Educação, Botucatu, v. 4, n. 7, p. 25-36, 2000.

${ }^{23}$ Cf. GRIJÓ. Luiz Alberto. A mídia no século XXI: desafios da pesquisa histórica. In: DELGADO, Lucília de Almeida Neves; FERREIRA, Marieta de Moraes (Org.). História do tempo presente. Rio de Janeiro: Ed. FGV, 2014. p. 279-298.
} 
sua vez, julga que os sinais que irrompem no presente tornam os vestígios uma "marca documental" e "pensar a mudança como parte do processo, no qual estão envolvidos particularismos, repetições, restos, que o passado legou ao presente, é fundamental na operação historiográfica".

No campo teórico, a História e a Comunicação também se cruzam por meio da ligação existente entre a História Social inglesa, especialmente inovadora dentro da historiografia por desenvolver a chamada "história vista de baixo", e os Estudos Culturais, campo interdisciplinar aclamado entre os comunicólogos, ambos inaugurados por nomes como E. P. Thompson, Raymond Willians e outros. Jesús Martín-Barbero (2008, p. 249251), também integrado aos Estudos Culturais, ao fazer reflexões sobre o cruzamento entre a História e a Comunicação em referência ao campo educacional, inferindo também sobre a assimilação de historicismos por parte de grupos sociais da contemporaneidade, pondera que:

Vivemos uma forte des-historização da sociedade em benefício do presente e de valorização absoluta, isto é, uma perigosa perda da memória. [...] Necessitamos construir uma história que, partindo de alguns fatos-chave do presente mais próximo, nos permita situá-los na escala mais larga do tempo longo, colocar hoje em perspectiva, ou seja, desnaturalizar o óbvio e evitar os determinismos de toda a espécie.

Com toda certeza, uma resposta para essas questões seria a própria História do Tempo Presente, que, muitas vezes, anuncia o acontecimento "do agora" como já pertencente à História e são inúmeros os exemplos: "A saída das operárias da fábrica” projetada pelo cinematógrafo de Auguste e Louis Lumière, em 1895, os discursos inflamados de Hitler, o afrontamento do jovem chinês a tanques de guerra na Praça da Paz Celestial, em 1989, a chegada do homem à Lua, em 1969, o choque dos aviões com as torres do World Trade Center, em 11 de setembro de 2001, as movimentações, a partir de 2010, que culminaram na Primavera Árabe ou mesmo a votação do impeachment de Dilma Rousseff, em 2016, todos são acontecimentos que foram registrados já com a predestinação de serem fatos históricos e, nesse momento, vemos com maior distinção os enlaces entre a História e a Comunicação, entre o saber histórico e as mídias, a capacidade de registro do presente e seu reconhecimento e enquadramento em um contexto mais amplo da História. 


\section{Historiador x jornalista}

Aparentemente, os métiers do historiador e do jornalista são opostos; enquanto um se preocupa com o passado, o outro se ocupa do presente. Entretanto, parece óbvia a relação existente entre os historiadores do presente e os jornalistas, pois ambos estão interessados nos acontecimentos do momento, "do agora" e têm seus ofícios calcados na "ordem do dia", no "instante presente" e, de acordo com Jean-Pierre Rioux (1999, p. 119), a História do Tempo Presente não teria surgido sem esse "provocante", mas “frutífero", encontro "entre historiadores sedentos de atualidade e jornalistas em busca de legitimidade histórica".

Os jornalistas, apesar de elegerem o presente e prioritariamente "administrar a efemeridade" do hoje, frequentemente se voltam ao passado em suas produções, mas correndo o risco de fazer regressões muito longas, causando o desinteresse no leitor, explanações mal fundamentadas ou "deslizes ideológicos". O historiador que se interessa pelo presente, por sua vez, pode tornar-se excessivamente midiático, ao concorrer com o jornalista na exposição de novidades e espaço nas mídias, ou obsoleto, na medida em que as fontes e temas aos quais recorre e que aborda são de grande volatilidade. Nesse ponto, como esclarece Rioux (1999, p. 120), também cabe ao historiador a distinção entre o perdurável e o efêmero e a tentativa de situar os acontecimentos em limites mais consideráveis de tempo ou, como tentamos demonstrar, diferenciando o "imediato" e o "presente". Isso confere ao historiador o "papel de demiurgo", como sugere Rioux (1999), ou o "voto de Minerva", sobre o que, dentre o que é produzido no presente, perpetuar-se-á na História.

Expressões como “o jornalista é o historiador do presente”, “o jornalista é o historiador do cotidiano", "o repórter é o historiador do presente", "historiador do imediato", "a História acontece a todo o momento", "as páginas de um jornal podem ir para o lixo ou entrar para a História”, “o jornalista é testemunha da História” ou "a testemunha ocular da História", só demonstram ainda mais as aproximações entre os dois ofícios. O que é registrado hoje pelos jornalistas (poderíamos incluir os fotógrafos, câmeras, cineastas etc. - processo dinamizado pelo surgimento das mídias eletrônicas móveis, permitindo aos cidadãos comuns o registro dos vários acontecimentos), apesar 
de corresponder ao agora, logo servirá de fonte para os historiadores, embora ainda passe pela seleção natural da permanência e da duração. Do mesmo modo como o que é feito pelos historiadores serve para o embasamento do material produzido pelos jornalistas. No caso de ambos optarem pela observação do presente, há uma disputa fraterna entre os ofícios, o que só contribui para a atualização e o aprofundamento das produções. Um grande erro, nesse caso, é o historiador buscar incessantemente, tal como o jornalista, a "notícia instantânea" ou os "furos de reportagem", pois se isso atribui notoriedade e ineditismo ao jornalista, no campo da História leva a um risco extremo de ampliar a efemeridade das fontes e dos temas abordados.

Sobre a missão atribuída ao jornalista, Ricardo Kotscho (apud REIMBERG, 2015, p. 53), ainda que em tom saudosista, afirmou que: "repórter tem que sujar os sapatos. Tomar sol, tomar chuva, tem que ir aos lugares, ir atrás das histórias, e não ter informações de segunda mão, terceira mão, quarta mão, como é hoje”. Entretanto, apesar de correrem atrás da notícia esperando alcançar o ineditismo, corrida esta que por vezes se torna um "vale tudo", os jornalistas têm, ou procuram manter, um compromisso com a verdade, justificando seu lema “a verdade em primeira mão", em concordância com o ideal iluminista de esclarecimento, de "dizer a verdade" ${ }^{24}$. Sylvia Moretzsohn (2002, p. 55) esclarece que: "os princípios do jornalismo baseiam-se na ideia de 'esclarecer os cidadãos', relacionada a critérios de objetividade que dizem respeito ao suposto poder de 'verdade' contido nos próprios fatos". Porém, é claro que existem os profissionais mal intencionados, pertencentes à chamada "imprensa marrom" (yellow press, em inglês), que veiculam notícias falsas, ou falseadas ("fake news"), o que pode ter consequências catastróficas e só vem a denegrir o ofício dos "homens de imprensa". O campo da História também tem seu compromisso com a verdade: não cabe ao historiador mentir, para isso ele pode recorrer à ficção, e ainda Ihe é permitido em maior grau não omitir, devido ao distanciamento dos fatos. Porém, sem dúvida, o historiador tem maior possibilidade de manejo das fontes e dos fatos, o que lhe permitiria não só omitir, mas também falsear ou mascarar, a verdade com mais facilidade e sem necessariamente ter

\footnotetext{
${ }^{24}$ Cf. MORETZSOHN, Sylvia. Jornalismo e esclarecimento: um cotidiano exercício de suspensão. Verso e
} Reverso, São Leopoldo, v. 21, n. 48, 2007. 
uma cobrança imediata, como ocorre com o jornalista. Outro fator determinante no falseamento das notícias, ao menos no Brasil, é a pressão diária sofrida pelos jornalistas que, em geral, trabalham em conjunturas privadas, e até familiares, nas quais a omissão ou o desvelamento de informações pode incorrer na garantia de trabalho (muitas vezes precarizado e danoso) ou desemprego ${ }^{25}$, ao contrário do historiador, que, apesar de lutar contra grande concorrência e falta de oportunidades, geralmente exerce as funções de professor e/ou pesquisador com maior respaldo de instituições, em grande parte públicas.

Também devido à força de manipulação da verdade, diante da opinião pública ${ }^{26}$, a mídia (de modo geral, mas alguns conglomerados mais enfaticamente) também é vista como um "quarto poder", rivalizando com o Legislativo, Executivo e Judiciário no controle dos cidadãos. Próximo a isso, também podemos dizer que outra semelhança entre historiadores e jornalistas é o engajamento político que, voluntária ou involuntariamente, termina refletindo em suas produções e, algumas vezes, influencia leitores e espectadores, destarte a pretensa imparcialidade a que se propõem. Entretanto, os jornalistas, embora pareçam livres para dizer o que querem, e até as leis que defendem a liberdade de expressão e de imprensa os amparam nisso, têm ao menos o compromisso de escrever sob os olhares atentos e críticos de seus leitores, o que os limita, em grande parte, sobre o que e como dizer, até mesmo se operando "uma radical redução do universo linguístico do jornalismo, geralmente associada à ideia de inteligibilidade ou simplicidade" (MARCONDES FILHO, 2000, p. 44). Além das pressões editoriais sofridas diariamente nos locais de trabalho, como já mencionamos. O mesmo ocorre com o historiador do presente, que, embora seja justificado pelo enquadramento de sua escrita em um contexto mais amplo, o da História, também sofre críticas imediatas

25 Para um melhor panorama das dificuldades na carreira, danos e precarização do jornalismo, cf. MARCONDES FILHO, Ciro. Comunicação e jornalismo: a saga dos cães perdidos. São Paulo: Hacker, 2000. Ver também: REIMBERG, Cristiane Oliveira. O exercício da atividade jornalística na visão dos profissionais: sofrimento e prazer na perspectiva teórica da psicodinâmica do trabalho. 376 f. Tese (Doutorado) - Programa de Pós-Graduação de Ciências da Comunicação, Universidade de São Paulo, 2015.

${ }^{26}$ Segundo Ciro Marcondes Filho (2000, p. 17): “opinião pública é a condensação das posições e das preferências num determinado momento, oriundas dos debates ocorridos na esfera pública". 
de quem o lê e, principalmente, por fazer referência a personagens também do presente, ou seja, ainda em vida.

Os jornalistas já foram vistos como os melhores cronistas do século $\mathrm{XX}$, devido às dificuldades por parte dos historiadores para tratar desse período, causada, especialmente, pela proximidade temporal. A história do presente está, portanto, marcada pelo crivo dos jornalistas: "de certa maneira ela é mesmo filha da imprensa" (CHAVEAU e TÉTART, 1999, p. 22). Os historiadores da década de 1960, no entanto, sentiram o dever de entrar nos debates do presente, antes dominados por jornalistas, sociólogos, politólogos, economistas, etnólogos, entre outros, também para evitar que o acontecimento, ou fato histórico, fosse narrado com uma linguagem extremamente jornalística e ainda para satisfazer seu desejo de conhecimento do agora. Chaveau e Tétart (1999) ressaltam que universitários e intelectuais já haviam inaugurado análises sobre a imprensa na primeira metade do século XX, patenteadas depois pela universidade e pelos trabalhos de René Rémond e de Jean Lacouture.

Robert Frank (1999), de modo semelhante ao que vimos com Rioux (1999), acredita que a história do presente se caracteriza pela "reflexão crítica no tempo", pela “espessura da duração", mesmo que seja de um "passado próximo" e não tão "longínquo". Para o autor, "é essa consideração do longo termo que faz a diferença fundamental entre 'história do presente' e o trabalho sobre a 'atualidade', entre o historiador e o jornalista" (FRANK, 1999, p. 117). No entanto, como já vimos, Lagrou (2009, p. 32) mostra que Timothy Garton Ash, em 1999, publicou o livro History of the present “com esboços dos acontecimentos da Europa Central desde 1989”, no qual fala que:

A história "muito recente" ou ainda "as questões correntes" seriam um terreno abandonado pelos jornalistas, logo que seca a tinta de seus jornais, e desprezado pelos historiadores que negligenciam, assim, as novas oportunidades proporcionadas pela reportagem televisiva ao vivo, estilo CNN, que ofereceria um acesso sem precedente aos acontecimentos e protagonistas. De qualquer forma, devido ao uso crescente do telefone e do alcance do e-mail, esses protagonistas produziriam cada vez menos traços escritos de suas atividades que permitiriam aos historiadores descobri-los nos arquivos, trinta anos mais tarde. 
Vale destacar, no entanto, que as novas tecnologias, como já tentamos demonstrar, são cada vez mais incorporadas ao métier do historiador e, consequentemente, seus diversos recursos como mensagens de e-mails e redes sociais, que se apresentam como novidades (assim como outrora o fora a imagem televisiva, 0 cinema etc.), também encontram, aos poucos, maior aceitação como fontes de pesquisa. Nesse sentido, Luiz Alberto Grijó (2014, p. 283-284) chama a atenção para o fato de estarse impondo aos jornalistas um novo lugar para a "opinião pública”, a internet, que passa a representar o mesmo que antes fora a "voz das ruas", também substituindo suas fontes de informação, antes encontradas na sociabilidade cotidiana proporcionada por caminhadas, cafés, bares, restaurantes etc. Para Ciro Marcones Filho (2000, p. 30): “a informação produzida e circulante nas [redes] incide adicionalmente sobre o papel histórico do jornalista como um 'contador de histórias' (repórter) mas também como um ‘explicador do mundo' (analista/comentarista)”. O mesmo ocorre com o historiador, que tem na internet uma infinidade de fontes, as quais pode consultar a todo momento (levando-se em conta sua descartabilidade), substituindo arquivos e bibliotecas, além de livros, jornais e revistas impressos, e possibilitando, ainda, publicações em linha, por meio de sites, blogs, livros digitais (como Portable Document Format - PDF -, e-book etc.), embora haja certa ilusão ao acreditar na promessa de "informações novas a cada instante" 27 .

Essas publicações disponibilizadas em rede (web), apesar de também produzidas pelos historiadores, são prioritariamente pertencentes ao ofício dos jornalistas, uma nova forma de produção jornalística, dentro dos domínios da cibercultura, que foi denominada ciberjornalismo, ou, mais usualmente, webjornalismo.

Também devemos observar que, nos dias atuais, devido à constante busca pelos já mencionados "furos de reportagem", as notícias são transmitidas até de forma instantânea, "em tempo real”, diariamente, e, por vezes, em nível global, o que dificulta, mas catalisa o trabalho do jornalista, embora Sylvia Moretzsohn (2002, p. 55) alerte que há uma tendência à eliminação da "necessidade de veicular informações corretas e

\footnotetext{
${ }^{27}$ Cf. MORETZSOHN, Sylvia. Jornalismo em “tempo real”: o fetiche da velocidade. Rio de Janeiro: Revan, 2002, p. 133-135.
} 
contextualizadas", sendo tudo válido para "sustentar a notícia transmitida instantaneamente". Ao historiador, a notícia em tempo real possibilita a compreensão exata das questões que quer abordar, pois se depara tête-à-tête com o acontecimento. Sobre essa questão, Ana Maria Mauad (2007, p. 223-228) se refere aos atentados contra o World Trade Center, em Nova York, em 11 de setembro de 2001:

Um "acontecimento monstruoso" (NORA, 1979), transmitido em tempo real pelas principais redes de televisão do mundo, que abalou o mundo e suscitou reações as mais díspares - alegria e pesar, comemoração e luto, revolta e regozijo. No calor dos combates em torno da versão verdadeira dos fatos, teceram-se as diferentes interpretações envolvendo, na sua construção, os tempos e entretempos históricos [e acrescenta que é] justamente na possibilidade de associar a transmissão em tempo real e o caráter informativo atribuído aos noticiários à dimensão de consumo que as mídias carregam no mundo atual que os acontecimentos conquistam a sua hiper-realidade de divertimento dramático: todo mundo e ninguém tomam parte.

A busca pelo tempo real tem origens na formação da sociedade industrial, na qual ocorre uma grande aceleração, o "tempo natural” é substituído pelo "tempo das fábricas" e o "tempo histórico" dá lugar ao "tempo cronológico", processo sintetizado em aforismos como time is money, de Benjamin Franklin, ou rush or perish, como rezam as leis de mercado. Esse quadro se reflete no jornalismo por meio de uma fetichização da velocidade, na qual a notícia tem de ser imediata. Todavia, a notícia que chega neste exato instante desperta a sensação de simultaneidade e, com isso, de proximidade, de união, de conexão e, também, de movimento e de andamento, como revela Pierre Lévy (1993, p. 114): "a noção de tempo real, inventada pelos informatas, resume bem a característica principal, o espírito da informática: a condensação no presente, na operação em andamento. O conhecimento de tipo operacional oferecido pela informática está em tempo real".

Segundo Márcia Maria Menendes Motta (2012, p. 32): “o número, às vezes incomensurável de fontes, dificulta certamente a análise e demarca uma fronteira às vezes fluida entre a informação jornalística e a análise histórica”. Porém, notamos que os historiadores bebem na fonte dos jornalistas ou, como quer Rioux (1999, p. 41), “tomam a sopa do dia no noticiário da TV". Todavia, os que produzem a História devem saber que 
ela deve fugir do efêmero e, no presente, como também sugere Rioux (1999, p. 41), evitar extrair os acontecimentos com certas distorções causadas pela "mediatização do acontecido, ideologização do ato e efeitos de moda", embora Jean-Jacques Becker (1999, p. 66) considere que:

O historiador, queira ou não, sofre os efeitos da moda, não por "parisianismo", mas porque mesmo se trabalha e pesquisa como quer, onde quer, sobre o que ele quer, seu esforço é mais ou menos sustentado pelo interesse dos editores, das revistas, dos outros historiadores, da opinião de modo global...

Além disso, há casos em que os dois ofícios se confundem ou ocorre um pool, para recorrer a um termo utilizado pela imprensa. Chaveau e Tétart (1999, p. 23) chamaram Jean Lacouture de “jornalista-historiador” e Charles André de “historiador-jornalista”. O historiador norte-americano Robert Darnton, além de ter escrito sobre literatura e sobre imprensa, também foi repórter do The New York Times no início dos anos 1960. No Brasil, como vimos, Nelson Werneck Sodré, historiador e militar, ainda hoje é referência na História da Imprensa, assim como Marialva Barbosa também transita entre a História a Comunicação. Podemos destacar, ainda, a obra do jornalista ítalo-brasileiro Elio Gaspari sobre a ditadura militar no Brasil, que, além dos conhecidos quatro volumes publicados entre 2002 e 2004, ganhou, em 2016, mais um volume, intitulado Ditadura acabada, e muitos outros cruzamentos semelhantes, de historiadores que estudam meios de comunicação, imprensa etc. e de jornalistas e/ou comunicólogos que se valem do campo histórico.

\section{Conclusão}

Procuramos demonstrar as diferenças e semelhanças entre historiadores e jornalistas que, notadamente, ocorrem no âmbito da história presente. Se, por acaso, a insurgência da História do Tempo Presente se deve à atividade jornalística, o jornalismo também deve, em grande medida, tributo ao saber histórico. Em contrapartida, os jornalistas auxiliam os historiadores a trazer o passado de volta à tona, especialmente para as novas gerações, que têm cada vez mais as mídias eletrônicas como recursos na 
busca pelo conhecimento. Esses são cruzamentos inevitáveis nos dias atuais e o melhor a ser feito é a colaboração mútua, compreendendo as inter-relações e os elos existentes entre esses dois ofícios. Podemos concluir tomando como nosso o pensamento de Jacques Le Goff (1999, p. 101-102) sobre seus anseios em relação aos historiadores do presente e os jornalistas:

O que espero dos historiadores da difícil história imediata [ou do tempo presente], inclusive dos jornalistas, que, se fizerem bem seu ofício, são verdadeiros historiadores da história imediata, são quatro atitudes:

- ler o presente, o acontecimento, com uma profundidade histórica suficiente e pertinente;

- manifestar quanto a suas fontes o espírito crítico de todos os historiadores segundo os métodos adaptados a suas fontes;

- não se contentar em descrever e contar, mas esforçar-se para explicar;

- tentar hierarquizar os fatos, distinguir o incidente do fato significativo e importante, fazer do acontecimento aquilo que permitirá aos historiadores do passado reconhecê-lo como outro, mas também integrá-lo numa longa duração e numa problemática na qual todo os historiadores de ontem e de hoje, de outrora e do imediato, se reúnam. 


\section{Referências}

BARBOSA, Marialva. História cultural da imprensa: Brasil - 1800-1900. Rio de Janeiro: Mauad X, 2007.

BARBOSA, Marialva. História cultural da imprensa: Brasil - 1900-2000. Rio de Janeiro: Mauad X, 2010.

BECKER, Jean-Jacques. Marxismo e comunismo na história recente. In: CHAVEAU, Agnès; TÉTART, Philippe (Org.). Questões para a história do presente. Bauru, SP: Edusc, 1999. p. 61-72.

BÉDARIDA, François. Tempo presente e presença da história. In: FERREIRA, Marieta de Moraes; AMADO, Janaína. Usos e abusos da história oral. Rio de Janeiro: Ed. FGV, 1998. p. 219-229.

BRAUDEL, Fernand. História e ciências sociais. A longa duração. In: BRAUDEL, Fernand. Escritos sobre a história. São Paulo: Perspectiva, 2009. p. 41-78.

BURKE, Peter. A Comunicação na História. In: RIBEIRO, Ana Paula Goulart; HERSCHMANN, Micael (Org.). Comunicação e história: interfaces e novas abordagens. Rio de Janeiro: Mauad X/Globo Universidade, 2008. p. 61-81.

CALABRE, Lia. A era do rádio. Rio de Janeiro: Zahar, 2002.

CHAVEAU, Agnès; TÉTART, Philippe. Questões para a história do presente. In: CHAVEAU, Agnès; TÉTART, Philippe (Org.). Questões para a história do presente. Bauru, SP: EdusC, 1999. p. 9-37.

DELGADO, Lucília de Almeida Neves; FERREIRA, Marieta de Moraes (Org.). Introdução. In: DELGADO, Lucília de Almeida Neves; FERREIRA, Marieta de Moraes (Org.). História do tempo presente. Rio de Janeiro: Ed. FGV, 2014. p. 7-12.

DOSSE, François. A história. São Paulo: Ed. Unesp, 2012.

FERREIRA, Marieta de Moraes. História do tempo presente: desafios. Cultura Vozes, Petrópolis, v. 94, n. 3, p. 111-124, maio/jun. 2000.

FERREIRA, Marieta de Moraes; AMADO, Janaína. Usos e abusos da história oral. Rio de Janeiro: Ed. FGV, 1998.

FICO, Carlos. História do tempo presente, eventos traumáticos e documentos sensíveis: o caso brasileiro. Varia Historia, Belo Horizonte, v. 28, n. 47, p. 43-59, jan./jun. 2012. 
FIORUCCI, Rodolfo. Considerações acerca da história do tempo presente. Revista Espaço Acadêmico, Maringá, n. 125, p. 110-121, out. 2011.

FRANK, Robert. Questões para a fonte do presente. In: CHAVEAU, Agnès; TÉTART, Philippe (Org.). Questões para a história do presente. Bauru, SP: Edusc, 1999. p. 103-118.

GARCIA, Patrick. Essor et enjeux de l'histoire du temps présent au CNRS. La Revue pour L'Histoire du CNRS, n. 9, 2003.

GONÇALVES, Márcio Souza; SAINT CLAIR, Ericson Telles. Comunicação e história: perspectivas analíticas. In: RIBEIRO, Ana Paula Goulart; HERSCHMANN, Micael (Org.). Comunicação e história: interfaces e novas abordagens. Rio de Janeiro: Mauad X/Globo Universidade, 2008. p. 45-58.

GRIJÓ. Luiz Alberto. A mídia no século XXI: desafios da pesquisa histórica. In: DELGADO, Lucília de Almeida Neves; FERREIRA, Marieta de Moraes (Org.). História do tempo presente. Rio de Janeiro: Ed. FGV, 2014. p. 279-298.

HALL, Stuart. A identidade cultural na pós-modernidade. 11. ed. Rio de Janeiro: DP\&A, 2006.

HARTOG, François. Regimes de historicidade. Belo Horizonte: Autêntica, 2013.

HOBSBAWM, Eric. Sobre história: ensaios. São Paulo: Companhia das Letras, 1998.

KOSELLECK, Reinhart. Futuro passado: contribuição à semântica dos tempos históricos. Rio de Janeiro: Contraponto, 2006.

LAGROU, Pieter. Sobre a atualidade da história do tempo presente. In: PÔRTO JR., Gilson (Org.). História do tempo presente. Bauru, SP: Edusc, 2007. p. 31-45.

LAGROU, Pieter. A história do tempo presente na Europa depois de 1945: como se constituiu e se desenvolveu um novo campo disciplinar. Revista Eletrônica Boletim do Tempo, São Cristóvão, v. 4, n. 15, 2009.

LE GOFF, Jacques. A visão dos outros: um medievalista diante do presente. In: CHAVEAU, Agnès; TÉTART, Philippe (Org.). Questões para a história do presente. Bauru, SP: Edusc, 1999. p. 93-102.

LENE, Hérica; SELIDONHA, Francisca. Entre comunicação e história: O indiciarismo como metodologia para pesquisas históricas sobre imprensa. Em Questão, Porto Alegre, v. 18, n. 1, p. 31-44, jan./jul. 2012. 
LÉVY, Pierre. As tecnologias da inteligência: o futuro do pensamento na era da informática. São Paulo: Ed. 34, 1993.

MACIEL, Suellen Neto Pires. Disputas da memória: uma reflexão inicial sobre a lei de criação da Comissão Nacional da Verdade: In: DELGADO, Lucília de Almeida Neves; FERREIRA, Marieta de Moraes (Org.). História do tempo presente. Rio de Janeiro: Ed. FGV, 2014. p. 116-133.

MARCONDES FILHO, Ciro. Comunicação e jornalismo: a saga dos cães perdidos. São Paulo: Hacker, 2000.

MARTÍN-BARBERO, Jesús. Saberes hoje: disseminações, competências e transversalidades. In: RIBEIRO, Ana Paula Goulart; HERSCHMANN, Micael (Org.). Comunicação e história: interfaces e novas abordagens. Rio de Janeiro: Mauad X/Globo Universidade, 2008. p. 237-252.

MARTINO, Luiz C. Classificação e exame crítico da literatura sobre História da Comunicação. In: RIBEIRO, Ana Paula Goulart; HERSCHMANN, Micael (Org.).

Comunicação e história: interfaces e novas abordagens. Rio de Janeiro: Mauad XVGlobo Universidade, 2008. p. 27-43.

MAUAD, Ana Maria. Dimensões do presente: palavras e imagens de um acontecimento, os atentados ao World Trade Center e ao Pentágono, em 11 de setembro de 2001. In: PÔRTO JR., Gilson (Org.). História do tempo presente. Bauru, SP: Edusc, 2007. p. 223-263.

MCLUHAN, Marshall; FIORE, Quentin. Guerra e paz na aldeia global. São Paulo/Rio de Janeiro: Record, 1971.

MONTEIRO, José Fernando S. Música na TV: a televisão na difusão da música popular brasileira e a mimese através dos programas musicais. In: ALBUQUERQUE, Luiz Botelho; ROGÉRIO, Pedro; NASCIMENTO, Marco Antonio (Orgs.). Educação musical: reflexões, experiências e inovações. Fortaleza: Ed. UFC, 2015. p. 121-148.

MORETZSOHN, Sylvia. Jornalismo em "tempo real": o fetiche da velocidade. Rio de Janeiro: Revan, 2002.

MORETZSOHN, Sylvia. Jornalismo e esclarecimento: um cotidiano exercício de suspensão. Verso e Reverso, São Leopoldo, v. 21, n. 48, 2007.

MOTTA, Márcia Maria Menendes. História, memória e tempo presente. In: CARDOSO, Ciro Flamarion; VAINFAS, Ronaldo (Org.). Novos domínios da história. Rio de Janeiro: Elsevier, 2012. p. 20-36. 
MULLER, Helena Isabel. História do tempo presente: algumas reflexões. In: PÔRTO JR., Gilson (Org.). História do tempo presente. Bauru, SP: Edusc, 2007. p. 17-29.

NORA, Pierre. O retorno do fato. In: LE GOFF, Jacques; NORA, Pierre. História: novos problemas. 2. ed. Rio de Janeiro: Francisco Alves, 1979. p. 179-193.

PÔRTO JR., Gilson (Org.). História do tempo presente. Bauru, SP: Edusc, 2007.

PUENTES, Johnny Alarcón; GAVÍDIA, J. L. Mozant. História e historiografia: construção de novas tendências teóricas. In: PÔRTO JR., Gilson (Org.). História do tempo presente. Bauru, SP: Edusc, 2007. p. 297-309.

\section{REIMBERG, Cristiane Oliveira. O exercício da atividade jornalística na visão dos} profissionais: sofrimento e prazer na perspectiva teórica da psicodinâmica do trabalho. 376 f. Tese (Doutorado) - Programa de Pós-Graduação de Ciências da Comunicação, Universidade de São Paulo, 2015.

REIS FILHO, Daniel Aarão. As organizações comunistas e a luta de classes no Brasil: 19611968. Tese (Doutorado) - Programa de Pós-Graduação em História Social, Universidade de São Paulo, 1987.

REIS FILHO, Daniel Aarão. A revolução faltou ao encontro. São Paulo: Brasiliense, 1990.

RIBEIRO, Ana Paula Goulart; HERSCHMANN, Micael. História da comunicação no Brasil: um campo em construção. In: RIBEIRO, Ana Paula Goulart; HERSCHMANN, Micael (Org.). Comunicação e história: interfaces e novas abordagens. Rio de Janeiro: Mauad X/Globo Universidade, 2008. p. 13-26.

RIOUX, Jean-Pierre. Entre história e jornalismo. In: CHAVEAU, Agnès; TÉTART, Philippe (Org.). Questões para a história do presente. Bauru, SP: Edusc, 1999. p. 119-126.

ROUSSO, Henry. A história do tempo presente, vinte anos depois. In: PÔRTO JR., Gilson (Org.). História do tempo presente. Bauru, SP: Edusc, 2007. p. 277-309.

RUBIM, Antonio Albino Canelas. A contemporaneidade como idade mídia. Interface Comunicação, Saúde, Educação, Botucatu, v. 4, n. 7, p. 25-36, 2000.

SALGADO, Lívia de Barros. Narrativas de dor e silêncio: tortura, clandestinidade e exílio na vida de homens e mulheres durante a ditadura brasileira. 149 f. Dissertação (Mestrado) - Programa de Pós-Graduação em Ciências Sociais, Universidade Federal Rural do Rio de Janeiro, 2015. 
SIRINELLI, Jean-François. Ideologia, tempo e história. In: CHAVEAU, Agnès; TÉTART, Philippe (Org.). Questões para a história do presente. Bauru, SP: Edusc, 1999. p. 73-92.

SKINNER, Quentin. Visões da política: sobre os métodos históricos. Algés: Difel, 2005.

SODRÉ, Nelson Werneck. Memórias de um soldado. Rio de Janeiro: Civilização Brasileira, 1967.

SODRÉ, Nelson Werneck. Memórias de um escritor. Rio de Janeiro: Civilização Brasileira, 1970.

VILLAÇA, Nízia. Práticas da comunicação e produção de sentido: entre Gutemberg e o ciberuniverso. In: RIBEIRO, Ana Paula Goulart; HERSCHMANN, Micael (Org.).

Comunicação e história: interfaces e novas abordagens. Rio de Janeiro: Mauad X/Globo Universidade, 2008. p. 253-266. 